\title{
Elisitasi Kebutuhan Untuk Meningkatkan Kepuasan Pengguna Pada Sistem E-Learning Universitas Muhammadiyah Malang
}

\author{
Much. Romadhoni ${ }^{*}$, Wahyu Andhyka Kusuma ${ }^{2}$ \\ 1,2Program Studi Teknik Informatika, Universitas Muhammadiyah Malang \\ *romadoni23.19@gmail.com
}

\begin{abstract}
Abstrak
Dalam beberapa tahun terakhir penggunaan sistem informasi telah berubah sangat dramatis. Saat ini banyak system informasi dikembangkan untuk berbagai macam pengguna. Berbagai macam pengguna ini memiliki berbagai karakteristik yang berbeda-beda, yang membuat organisasi yang mengembangkan system informasi sangat sulit untuk mengetahui kebutuhan penggunanya. Untuk itu diperlukan elisitasi kebutuhan yang baik dan mendalam untuk benar-benar mengetahui kebutuhan pengguna. Tujuan dari penelitian ini yaitu untuk menggali kebutuhan pengguna pada system E-Learning Universitas Muhammadiyah Malang untuk meningkatkan kepuasan pengguna system tersebut. Pada penelitian ini menggunakan beberapa metode elisitasi yaitu interview, storytelling, user persona, dan storyboard. Metode interview dilakukan untuk menggali permasalahan yang dialami pengguna pada saat menggunakan system. Kemudian hasil dari interview akan dioleh menjadi bentuk narasi storytelling dan kemudian dituangkan dalam sebuah dokumen persona. Dengan menggunakan metode diatas dapat menggali lebih dalam untuk mendapatkan solusi yang lebih tajam terhadap permasalahan yang dialami pengguna. Hasil dari keempat metode ini terbukti efektif digunakan untuk proses elisitasi kebutuhan karena keempat metode ini saling berkaitan serta melengkapi satu sama lain. Penelitian ini menghasilkan sebuah storyboard yang berisi rekomendasi solusi dari hasil penggalian kebutuhan yang dilakukan pada pengguna system E-Learning Universitas Muhammadiyah Malang.
\end{abstract}

Kata kunci: Elisitasi Kebutuhan, Interview, Storyboard, Storytelling, User persona

\begin{abstract}
In recent years the use of information systems has changed very dramatically. Currently, many information systems are developed for various types of users. These various kinds of users have different characteristics, which makes it very difficult for organizations developing information systems to know the needs of their users. For this reason, a good and in-depth need elicitation is needed to really know the user's needs. The purpose of this study is to explore the needs of users in the E-Learning system of the University of Muhammadiyah Malang to increase user satisfaction of the system. In this study, several elicitation methods were used, namely interviews, storytelling, user personas, and storyboards. The interview method is carried out to explore the problems experienced by users when using the system. Then the results of the interview will be processed into a narrative form of storytelling and then poured into a persona document. By using the above method, you can dig deeper to get a sharper solution to the problems experienced by users. The results of these four methods have proven to be effective in the need elicitation process because these four methods are interrelated and complement each other. This study resulted in a storyboard containing recommended solutions from the results of the excavation of needs carried out on users of the University of Muhammadiyah Malang E-Learning system.
\end{abstract}

Keywords: Interview, requirements elicitation, Storyboard, Storytelling 


\section{Pendahuluan}

Universitas Muhammadiyah Malang (UMM) merupakan perguruan tinggi swasta yang berada pada kota Malang, Jawa Timur. UMM termasuk dalam jajaran perguruan tinggi swasta terkemuka di Indonesia. Secara institusi kampus UMM telah mendapatkan akreditasi dengan peringkat " $\mathrm{A}$ ". Berdasarkan versi dari Unirank, UMM berada pada peringkat pertama universitas islam terbaik didunia. Melihat akreditasi serta peringkat tersebut, UMM terus berinovasi untuk meningkatkan mutu pendidikan Indonesia[1].

Salah satu bentuk inovasi tersebut telah diwujudkan dalam bentuk penyediaan sebuah system website bernama "LMS UMM". LMS UMM merupakan sebuah Learning Management System (LMS) pada kampus UMM, yang berperan untuk membuat, mendistribusikan, dan mengatur penyampaian konten pembelajaran berbasis web dimasa pandemi COVID-19 ini. System ini dapat membantu guru untuk mengelola bahan pembelajaran, mengelola nilai, mengelola aktivitas belajar siswa, dan menampilkan transkrip nilai. Tidak hanya guru yang dimudahkan dengan adanya sistem LMS, para siswa juga dapat dengan mudah mengakses konten pembelajaran dari mana saja dan kapan saja.

Hasil wawancara yang dilakukan peneliti kepada narasumber dari pihak pengguna menemukan pada system ini terdapat sebuah masalah utama yang sering dihadapi yang membuat kepuasan user menurun. Masalah utama ini yaitu pihak mahasiswa sering kali tidak mengetahui apa saja tugas yang harus di kerjakan atau quiz yang diberikan oleh pihak dosen, untuk itu mahasiswa harus mengecek satu per satu mata kuliah yang ada pada system untuk menemukan tugas atau quiz yang tersedia. Hal ini dilakukan karena pada menu dashboard LMS tidak ada layout untuk menampilkan tugas atau quiz yang tersedia dan juga menampilkan waktu deadline tugas atau quiz tersebut.

Berdasarkan permasalahan diatas perlu dilakukan penelitian untuk menggali kebutuhan atau elisitasi kebutuhan dari sistem LMS UMM secara mendalam, agar system LMS UMM memiliki user experience yang lebih baik. Proses elisitasi kebutuhan sangatlah penting, agar system yang dihasilkan memiliki fungsi yang sesuai dengan pengguna dari berbagai umur, jenis kelamin, dan pengetahuan.

Beberapa peneliti sudah meneliti cara bagaimana menggali kebutuhan suatu system dengan menggunakan metode tertentu, pada penelitian sebelumnya, melakukan elisitasi kebutuhan system ILAB dengan menggunakan metode user persona[2]. Penelitian lain dilakukan yang melakukan elisitasi kebutuhan dengan menggunakan Teknik use case[3]. Berbeda dengan riset sebelumnya, pada penelitian ini 
menggunakan metode interview, storytelling, user persona, dan storyboard.

Menurut Carrizo dkk., seorang insinyur perangkat lunak cenderung memilih teknik elisitasi data berdasarkan salah satu alas an berikut: (1) teknik tersebut merupakan satusatunya teknik yang mereka ketahui, (2) dalam semua situasi menggunakan teknik favorit mereka, (3) mereka menggunakan metodologi yang memiliki teknik tertentu, atau (4) teknik yang dipakai diduga efektif dalam situasi tersebut[4]. Karena beberapa alasan tersebut keputusan subjektif ini dapat membiaskan hasil elisitasi, menurunkan kualitas persyaratan output, dan berdampak pada hasil akhir kualitas perangkat lunak yang tidak maksimal. Para peneliti juga mengatakan bahwa analis atau pengembang perlu memperhatikan pemilihan teknik elisitasi sistematis dalam tahapan elisitasi kebutuhan.

Oleh karena itu, peneliti menggunakan empat metode yakni, interview, storytelling, user persona, dan storyboard, untuk meningkatkan kualiatas produk perangkat lunak akhir. Melalui empat metode tersebut, diharapkan dapat mengetahui kebutuhan pengguna yang nantinya akan meningkatkan kepuasan pengguna serta mampu memberikan rekomendasi perbaikan desain interface yang baik dan berkualitas.

\section{Tinjauan Pustaka}

\subsection{Penelitian Terkait}

Beberapa penelitian terkait dengan elisitasi kebutuhan sudah dipublikasikan, adapun diantaranya yakni:

Penelitian oleh Wahyuni dkk. tahun 2020[5]. Penelitian ini membahas tentang efektivitas teknik Human Computer Interaction $(\mathrm{HCl})$ berdasarkan identifikasi User Persona dalam proses pengembangan perangkat lunak (PL). Para peneliti mengimplementasikan Metode Cooper sebagai validasi agar dapat mengidentifikasi pola perilaku pengguna PL yang yang cocok dengan kebutuhan $\mathrm{HCl}$. Hasil menunjukkan bahwa dengan mengidentifikasi persona pengguna dalam elisitasi kebutuhan dapat menyelesaikan permasalahan yang digali secara mendetail. Metode ini terbukti unggul dibandingkan dengan tahap penggalian kebutuhan pada umumnya walau waktu yang dibutuhkan untuk prosesnya terbilang cukup lama. Berdasarkan hasil penelitian dapat dikatakan bahwa dengan metode persona, peneliti dapat merancang sistem $\mathrm{PL}$ dengan $\mathrm{HCl}$ yang lebih efektif.

Penelitian lainnya dilakukan oleh Prastuti dkk. pada tahun 2020[3]. Penelitian ini dilakukan untuk mengatasi permasalahan yang dihadapi sector pertanian masyarakat Kabupaten Batang. Proses distribusi hasil pertanian yang panjang menyebabkan kelompok petani tidak 
diuntungkan. Oleh karena itu, e-marketplace adalah solusi alternative bagi petani untuk menjual hasil taninya secara online. Tujuan penelitian dilakukan untuk membangun aplikasi e-marketplace tahap awal dengan memodelkan proses penggalian kebutuhan menggunakan Teknik use case. Hasil yang didapat yakni berupa model elisitasi kebutuhan fungsional dan elisitasi kebutuhan non fungsional yang digambarkan dengan diagram use case. Dari hasil diagram use case diharapkan terus dikembangkan untuk tahapan perancangan dan pembangunan atau coding dari aplikasi emarketplace.

Selanjutnya penelitian yang dilakukan oleh Kusuma dkk. pada tahun 2020[6]. Para peneliti menggunakan Persona yang merupakan Teknik $\mathrm{HCl}$ dalam menggali kebutuhan $\mathrm{PL}$ dalam sistem pengontrol bimbingan UMM. Dengan teknik tersebut, peneliti dapat mengidentifikasi karakteristik user dan mencapai suatu sistem PL yang baik dengan cara mengimplementasikan yang sesuai dengan apa yang dibutuhkan. Hasil yang didapat yakni dengan mengidentifikasi PL dapat memudahkan dalam menganalisa terkait kebutuhan sistem sehingga dapat dikembangkan sesuai dengan kebutuhan mahasiswa dan dosen sebagai user.

Berikutnya penelitian yang dilakukan oleh Sabariah dkk. pada tahun 2019[7]. Permasalahan penelitian terletak di pemilihan teknik elisitasi yang sesuai dengan karakteristik anak dalam menggali kebutuhan terhadap pembangunan aplikasi pembelajaran anak. Oleh karena itu, para peneliti membuat kerangka persyaratan elisitasi dalam aplikasi Pendidikan anak. Hal tersebut diharapkan dapat mempermudah pengembang aplikasi pembelajaran anak untuk mendapatkan produk aplikasi yang sesuai dengan usia perkembangan anak.

\subsection{Landasan Teori}

1. Interview

Interview atau wawancara merupakan teknik paling tradisional dan umum digunakan untuk elisitasi kebutuhan. Wawancara dapat dilakukan dengan cara yang berbeda, dan cara wawancara dapat memiliki pengaruh besar pada data yang dikumpulkan[8]. Efektifitas wawancara sangat bergantung pada kualitas interaksi diantara partisipan. Wawancara menyediakan cara yang efisien untuk mengumpulkan data yang cukup besar dengan waktu yang sangat cepat[9].

Ada dua jenis wawancara yang berbeda, yang pertama yaitu wawancara tertutup yang dimana pewawancara memiliki serangkaian pertanyaan yang telah ditentukan sebelumnya dan sedang mencari jawaban mereka. Yang kedua yaitu wawancara terbuka, di mana pewawancara dan stakeholder berdiskusi secara terbuka untuk 
mengetahui harapan mereka dari suatu sistem[10].

\section{Storytelling}

Storytelling merupakan cara yang sederhana untuk memahami komunikasi ide, keyakinan, dan pengalaman melalui cerita[11]. Mengaitkan sebuah cerita dengan apa yang dilakukan system dengan cerita bernarasi yang dapat dipahami lebih menarik, dan segera mengarah pada peningkatan proses pengumpulan informasi dan struktur informasi[12]. storytelling sangat efektif dalam mendukung, meningkatkan, dan melengkapi Teknik yang ada untuk fase elisitasi kebutuhan[12].

\section{User Persona}

Persona adalah metode yang mendefinisikan karakteristik pengguna dengan pola perilaku, tujuan, motivasi, dan harapan yang sama. Persona membantu memperjelas tujuan pengguna[13]. Persona tersebut dapat berasal dari data yang dikumpulkan dari wawancara, observasi atau kuesioner.

\section{Storyboard}

Storyboard merupakan sebuah sketsa memiliki urutan atau peristiwa yang dilalui pengguna dan sistem yang dirancang untuk mencapai tugas tertentu[14]. Storyboard berisi tentang informasi sektsa pengguna, aktivitas, perangkat, dan konteks system yang akan dibangun
3. Metode Penelitian

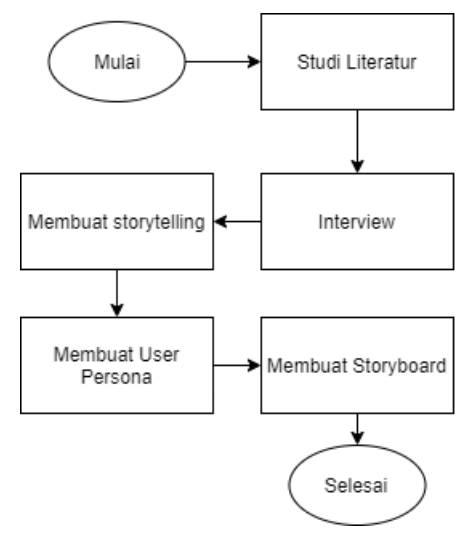

Gambar 1 Diagram alur metode penelitian

a. Studi Literatur

Tahapan studi literatur meruppakan tahapan untuk mengumpulkan penelitian terdahulu yang didapatkan dari jurnal, buku, dan artikel. Setelah mengumpulkan penelitian yang ada, maka peneliti akan menelaah tiap penelitian yang sekiranya cocok dengan penelitian yang sedang dilakukan oleh penulis untuk mendapatkan data-data dan Teknik yang bisa diterapkan pada penelitian ini.

b. Interview

Pada tahapan ini dilakukan wawancara terhadap pengguna yakni mahasiswa dan dosen, tahap interview dilakukan melalui media video conference seperti Google Meet atau Zoom, kemudian peneliti memberikan beberapa pertanyaan terkait kendala apa saja yang ditemui stakeholder atau pengguna dalam menggunakan system LMS UMM.

c. Storytelling 
Pada tahapan ini hasil dari interview akan narasikan dalam bentuk storytelling. Tahapan ini akan mengaitkan sebuah kebutuhan pengguna dengan apa yang dilakukan system dengan cerita bernarasi yang dapat dipahami lebih menarik.

d. User Persona

Tahapan membuat user persona berisi tentang dokumen persona yang menjelaskan deskripsi dari persona, deskripsi ini berisi komponen psikologi, motivasi, dan gaya hidup mereka[15]. Komponen ini didapatkan dari tahapan-tahapan sebelumnya.

\section{e. Storyboard}

Tahapan membuat storyboard merupakan tahapan yang berisi tentang bagaimana pembuatan raingkaian sketsa/cerita yang berisi tentang solusi dari kebutuhan yang berhasil di identifikasi pada tahap sebelumnya seperti interview, identifikasi kebutuhan, storytelling, dan user persona. Dengan data tersebut nantinya akan dijadikan bahan evaluasi dalam merancang perbaikan desain pada system. Tahap ini memiliki tujuan untuk melihat interaksi yang terjadi antara pengguna dan system.

\section{Hasil dan Pembahasan}

1. Hasil Interview

Setelah dilakukan pengumpulan data dengan wawancara dan observasi, didapati bahwa terdapat kendala yang saling berkaitan antara mahasiswa dan dosen dalam menggunakan system LMS UMM untuk melakukan kegiatan pembelajaran. Kendala tersebut yaitu :

2. Kendala Mahasiswa

mahasiswa merasakan kesusahan dalam melihat tugas apa saja yang sedang tersedia atau yang telah diberikan pihak dosen pada halaman dashboard, para mahasiswa merasa tidak nyaman karena mahasiswa harus mengecek satu persatu pada halaman mata kuliah yang mereka ambil pada system LMS untuk menemukan tugas apa yang telah diberikan oleh pihak dosen serta tenggat waktu pengumpulan tugas tersebut.

\section{Kendala Dosen}

seringkali dosen tidak menerima hasil dari tugas yang telah diberikan kepada mahasiswa. Dosen tidak mengetahui apakah mahasiswa tersebut memang tidak mnegerjakan atau mahasiswa tersebut tidak mnegetahui bahwa terdapat tugas yang diberikan pada halaman mata kuliah di system LMS UMM.

Setelah mengetahui kendala diatas, maka dapat diketahui bahwa mahasiswa membutuhkan daftar tugas yang belum dikerjakan dari berbagai matakuliah serta informasi tenggat waktu tugas yang diberikan pada halaman dashboard system 
LMS UMM. Halaman dashboard merupakan halaman yang dituju pengguna setelah melakukan proses login. Serta dari kendala diatas, pihak dosen menginginkan mahasiswa mengetahui tugas apa saja yang diberikan dosen dan berharap mahasiswa dapat mengerjakan dan menyerahkan tugas yang diberikan sesuai dengan waktu yang telah ditentukan.

\section{Storytelling}

Berdasarkan hasil interview dan kebutuhan pengguna diatas maka dapat dibuat sebuah storytelling seperti pada Tabel I.

Tabel 1. Narasi storytelling

\begin{tabular}{|c|c|c|}
\hline No & Pengguna & Storytelling \\
\hline 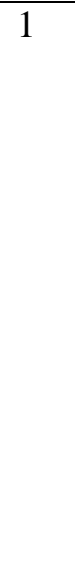 & Mahasiswa & $\begin{array}{l}\text { "Sebagai mahasiswa, } \\
\text { saya menginginkan daftar } \\
\text { tugas yang tersedia berada } \\
\text { pada halaman dashboard } \\
\text { LMS, sehingga saya dapat } \\
\text { mengetahui dengan } \\
\text { mudah tugas apa saja } \\
\text { yang telah diberikan oleh } \\
\text { dosen kepada saya dan } \\
\text { agar saya mendapatkan } \\
\text { nilai yang memuaskan } \\
\text { karena selalu mengerjakan } \\
\text { tugas yang diberikan." }\end{array}$ \\
\hline 2 & Dosen & $\begin{array}{l}\text { "sebagai dosen, saya } \\
\text { menginginkan mahasiswa } \\
\text { mengetahui tugas yang } \\
\text { saya berikan pada LMS } \\
\text { UMM serta saya } \\
\text { menginginkan mahasiswa } \\
\text { mengerjakan tugas dengan } \\
\text { baik dan juga } \\
\text { mengumpulkan tugas } \\
\text { yang saya berikan sesuai } \\
\text { dengan batas waktunya, } \\
\text { sehingga mahasiswa tidak } \\
\text { memiliki nilai yang } \\
\text { kosong dan mendapatkan }\end{array}$ \\
\hline
\end{tabular}

nilai yang bagus."

5. User Persona

Narasi pada storytelling yang telah dibuat pada tahap sebelumnya, didapatkan berbagai komponen yang berguna dalam pembuatan user persona, seperti nama, roles, task, frustration, dan goals. Komponen-komponen ini nantinya akan dimasukkan kedalam sebuah dokumen persona. Pada narasi ini juga didapatkan frustration dan tujuan dari masing-masing pengguna. frustration dan tujuan dari masingmasing pengguna ini menjadi dasar untuk membuat dokumen user persona seperti pada Gambar 1 dan Gambar 2.

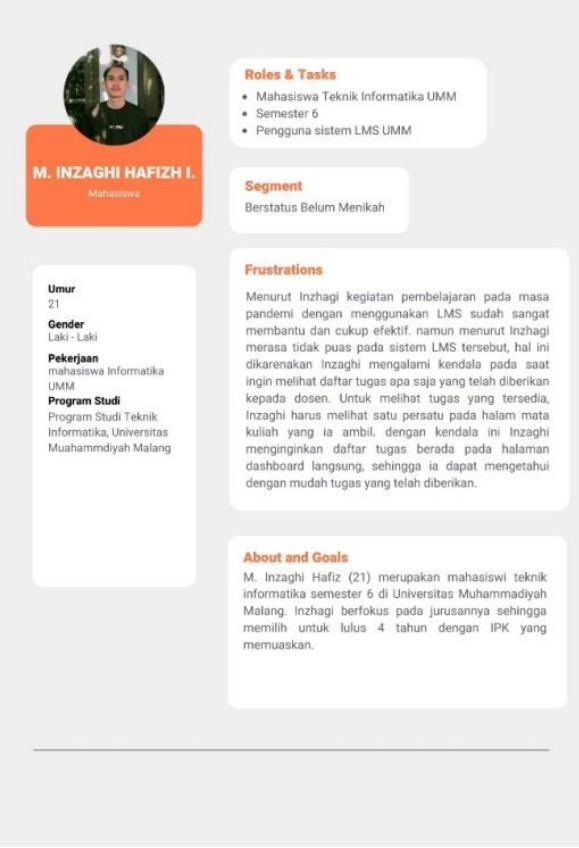

Gambar 2. User persona mahasiswa 


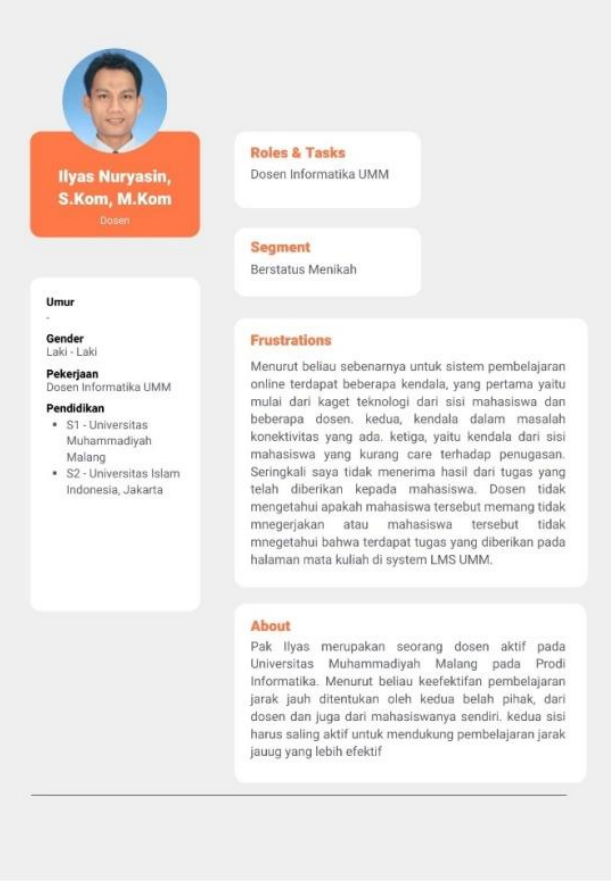

Gambar 3. User persona dosen

\section{Storyboard}

Dari semua user persona yang telah terkumpul, maka dapat dilakukan pembuatan storyboard. Stryboard dibuat berdasarkan user persona yang dikumpulkan dan semua pengetahuan atau kebutuhan yang dikumpulkan ketika proses elisitasi. Persona pada tahap sebelumnya digunakan sebagai actor dalam pembuatan storyboard. Storyboard pada Gambar 3 bukan gambaran seluruh system LMS, tetapi hanya bagian yang diperlukan saja dalam penelitian ini yang cukup untuk menjelaskan kebutuhan baru pada system LMS UMM.
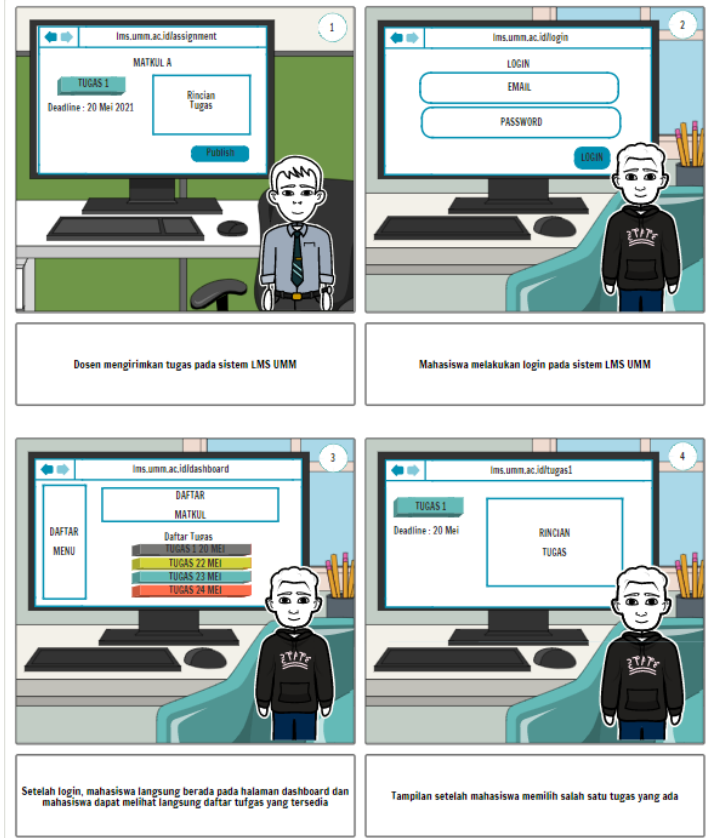

Gambar 4. Storyboard fitur rekomendasi

\section{Kesimpulan}

Dari kegiatan penelitian yang telah dilakukan dapat disimpulkan bahwa elisitasi menggunakan keempat metode diatas dapat menggali lebih dalam untuk mendapatkan solusi yang lebih tajam terhadap permasalahan yang dialami pengguna. Keempat metode ini efektif digunakan untuk proses elisitasi kebutuhan karena keempat metode ini saling berkaitan serta melengkapi satu sama lain. Dari penelitian yang telah dilakukan terhadap elisitasi kebuthan pada system LMS UMM, maka peneliti dalam memberikan saran untuk melakukan implementasi kepada system berdasarkan hasil storyboard yang ada pana penilitian ini. 


\section{Daftar Pustaka}

[1] "Top Islamic Universities in the world 2021 World University Ranking." https://www.4icu.org/top-religiousuniversities/islamic/ (accessed Jun. 06, 2021).

[2] W. A. Kusuma, A. Chathil, Y. Raditya, and N. Prakoso, "Elisitasi Kebutuhan Menggunakan User Persona," pp. 85-93, 2020.

[3] W. S , Prastuti Y.R, Christian Setianto, "Pemodelan Proses Elisitasi Kebutuhan Dengan Teknik Use Case (Studi Kasus : Pembangunan Aplikasi E-Marketplace Pertanian Pada Pemerintah Kabupaten Batang)," RISTEK J. Riset, Inov. dan Teknol., vol. 4, no. 2, pp. 73-83, 2020, [Online]. Available: http://ojs.batangkab.go.id/index.php/ristek /article/view/75.

[4] D. Carrizo, O. Dieste, and N. Juristo, "Systematizing requirements elicitation technique selection," Inf. Softw. Technol., vol. 56 , no. 6 , pp. 644-669, 2014, doi: 10.1016/j.infsof.2014.01.009.

[5] E. D. Wahyuni, W. A. Kusuma, H. R. Abdillah, and H. Y. Sari, "Perspektif Awam Dalam Implementasi Elisitasi Kebutuhan Menggunakan User Persona," Sistemasi, vol. 9, no. 3, p. 468, 2020, doi: 10.32520/stmsi.v9i3.854.

[6] D. P.-P. S. (Seminar T. dan and undefined 2021, "Elisitasi Kebutuhan Menggunakan User Persona Untuk Meningkatkan Pengalaman Pengguna Perangkat Lunak dalam Sistem Pengontrol Bimbingan," researchreport.umm.ac.id, Accessed: Jun. 27, 2021. [Online]. Available: http://researchreport.umm.ac.id/index.php/sentra/article/ view/3858.

[7] M. K. Sabariah, P. I. Santosa, and R. Ferdiana, "Requirement elicitation framework for child learning application A research plan," ACM Int. Conf. Proceeding Ser., pp. 129-133, 2019, doi:
10.1145/3305160.3305195.

[8] A. T. Chen, "Timeline drawing and the online scrapbook: Two visual elicitation techniques for a richer exploration of Illness Journeys," Int. J. Qual. Methods, vol. 17, no. 1, Dec. 2018, doi: 10.1177/1609406917753207.

[9] P. Spoletini, A. Ferrari, M. Bano, D. Zowghi, and S. Gnesi, "Interview review: An empirical study on detecting ambiguities in requirements elicitation interviews," in Lecture Notes in Computer Science (including subseries Lecture Notes in Artificial Intelligence and Lecture Notes in Bioinformatics), 2018, vol. 10753 LNCS, pp. 101-118, doi: 10.1007/978-3319-77243-1_7.

[10] S. Tiwari and S. S. Rathore, "A methodology for the selection of requirement elicitation techniques," arXiv, 2017.

[11] R. F. Ciriello, A. Richter, and G. Schwabe, "When prototyping meets storytelling: Practices and malpractices in innovating software firms," Proc. - 2017 IEEE/ACM 39th Int. Conf. Softw. Eng. Softw. Eng. Pract. Track, ICSE-SEIP 2017, pp. 163-172, 2017, doi: 10.1109/ICSE-SEIP.2017.24.

[12] N. Boulila, A. Hoffmann, and A. Herrmann, "Using Storytelling to record requirements: Elements for an effective requirements elicitation approach," 2011 4th Int. Work. Multimed. Enjoyable Requir. Eng. - Beyond Mere Descr. with More Fun Games, MERE'11 - Co-located with 19th IEEE Int. Requir. Eng. Conf., RE'11, no. August 2014, pp. 9-16, 2011, doi: 10.1109/MERE.2011.6043945.

[13] P. Jakkaew and T. Hongthong, "Requirements elicitation to develop mobile application for elderly," in 2nd Joint International Conference on Digital Arts, Media and Technology 2017: Digital Economy for Sustainable Growth, ICDAMT 2017, Apr. 2017, pp. 464-467, doi: 10.1109/ICDAMT.2017.7905013. 
Infotek : Jurnal Informatika dan Teknologi

Vol. 4 No. 2, Juli 2021

Hal. 228-237

e-ISSN 2614-8773

DOI : 10.29408/jit.v4i2.3602 Link : https://dx.doi.org/10.29408/jit.v4i2.3602

[14] R. Mollá, V. Santamarina-campos, and F. Abad, "Drones and the Creative Industry," Drones Creat. Ind., no. August, 2018, doi: 10.1007/978-3-319-95261-1.

[15] B. Warin, C. Kolski, and C. Toffolon,

"Living persona technique applied to $\mathrm{HCl}$ education," IEEE Glob. Eng. Educ. Conf. EDUCON, vol. 2018-April, pp. 51-59, 2018,

doi: 10.1109/EDUCON.2018.8363208. 